\title{
Prioritization of Reputation Loss Factors Imposed By Pipeline Failure Subject to Corrosion
}

\author{
Libriati Zardasti ${ }^{*}$, Norhazilan Md. Noor ${ }^{1}$, Nordin Yahaya ${ }^{1}$ \\ Department of Structure and Materials, Faculty of Civil Engineering, Universiti Teknologi Malaysia, 81310 Johor \\ Bahru, Johor, Malaysial \\ *Corresponding author: libriati@utm.my
}

\begin{abstract}
Reputation loss of a pipeline failure subject to corrosion is commonly neglected due to its qualitative nature. However, case studies found that perceptions of the stakeholders are prone to affect pipeline owner's long-term reputation. Identifying the influence factors is insufficient to assist the owner to respond if pipeline failure occurs. Thus, this article endeavors to prioritize the influential reputation loss factors by interviewing six experts of pipeline integrity management personnel. The analytic hierarchy process multicriteria decision making method was selected to help the prioritization process. Result shows that the most influenced factor is the loss of customer confidence (B1) and employee(s) caused accident (C9) ranked the least. The effort to quantify reputation loss can be substituted by prioritizing them according to stakeholders' preferences as an initial step to monetarily quantify these factors in future. Thus, a comprehensive pipeline risk assessment and the pipeline integrity management can be achieved and simultaneously improve the company's annual profit margin.
\end{abstract}

Keywords_reputation loss, pipeline, consequence assessment, analytic hierarchy process (AHP).

\section{INTRODUCTION}

$\mathrm{C}$ orrosion is one of the major causes of onshore pipeline accidents in the urban area [1,2]. Accidents caused by corrosion attack may cause multiple fatalities and injuries, serious financial loss, bad economic implications, and significant environmental damage that directly imposed to the stakeholders of the pipeline owner [3]. These impacts of pipeline failure consequences will eventually affects company's annual profit margins. Thus, there is a need to educate the pipeline owner that assessing overall consequences of pipeline failure impact is considerably essential. Hence, the evaluated total cost of failure should represent actual cost of pipeline damage in order to obtain a comprehensive and cost effective pipeline inspection and maintenance program (PIMP).

Various industries practice risk assessment to evaluate risk. Risk is the product of probability of failure (POF) or the magnitude and the consequence of failure (COF) or the impact of a failure event. The types of loss such as human, production, asset, environmental and reputation loss are taken into consideration to exhibit overall monetary loss due to a failure event. In the previous research related to consequence assessment of pipeline failure, reputation loss is commonly neglected due to the difficulties to quantifying the factors into monetary value $[4,5]$. Moreover, reputation is timedependent and it is event's impact-dependent [6,7]. An endeavor in assessing reputation loss for a pipeline accident was implemented according to the received coverage by media [8]. Unfortunately, it unable to represent the pipeline owner's stakeholders' actual perceptions as the reputation is defined as the beliefs of the stakeholders towards a company and its attributes [9]. Reputation is measured using an index based method and it is vital to most organizations [10]. Similar to the losses that can be counted monetarily, reputation loss is capable to affects company's profit margin as well [11]. Despite the qualitative nature of its characteristics, impact of loss of reputation significantly affects pipeline owner; it is an intangible asset that can contribute tangible or monetary losses.

For example, an explosion of a natural gas pipeline in San Bruno, California, owned by Pacific Gas and Electric Company (PG\&E) killed eight people, injured 58 others and destroyed 38 houses excluding 70 more damaged in a residential neighborhood on September 9, 2010. This event forced PG\&E to allocate 2.7 billion dollars approximately to pay charged fines and penalties by regulators four years later. Moreover, PG\&E was charged for diverting millions of dollar of allocation specifically for pipeline safety, to provide bonuses for executives years prior to the accident. Violation of integrity among personnel of the pipeline company initiated negative perception among their stakeholders; a sign of reputation decline as it is measured according to the stakeholders' perceptions [9].

Another case study of pipeline failure event owned by Columbia Gas Transmission Corporation (CGTC) shows similar impact on their company reputation as mentioned in the previous case. In Sissonville, West Virginia, an underground gas pipeline was ruptured on December 11, 2012 and luckily, there is no fatality or serious injuries recorded. However, the event costs three destroyed houses and 76 million standard cubic feet of high-pressure natural gas ignited 
and burned 820 feet wide and 1,100 feet along the pipeline right-of-way. CGTC spent about 8.4 million dollar and lost almost 285,000 dollar for pipeline repair and inspection and released gas, respectively. Corrosion was found as the main cause of the pipeline accident in the investigation process. It became worst when it was reported that no inspection had been done since 1988 on the pipeline. Irresponsibility had costs the company good reputation to be affected by the negative perception of the stakeholders against the integrity-breached employees. These factors influenced pipeline owner's credibility and simultaneously, the company reputation is endangered [9]. An effort to identify reputation loss has been done previously [12]; yet prioritizing the factors based on the stakeholder's perception is highly encouraged. If the pipeline operator are unable to attend their stakeholder's utmost important expectations, they may need to consider to face undescribable losses. Thus, it is crucial to prioritize the influencing factors which contribute to the loss of pipeline owner reputation in order to assist them to entertain their stakeholder's necessities and simultaneously unexpected damage with lucrative expenditures can be avoided.

\section{METHOD}

\section{A. Literature Search}

In-depth identification of factors was executed by identifying the negative responses documented in the online mass and electronic media and the pipeline accident reports which can be found publicly in several transportation safety websites [13]. They are the US Department of Transportation Pipeline and Hazardous Materials Safety Administration (PHMSA), an independent U.S. government investigative agency known as the National Transportation Safety Board (NTSB), an independent agency that investigate occurrences of event on transportation safety named the Transportation Safety Board of Canada (TSB), the owner of an extensive gas pipeline-incident database the European Gas pipeline Incident data Group (EGIG), and etc. Based on 10 cases of pipeline failure from various countries due to corrosion attack, a number of 22 reputationthreat factors have been successfully identified [14]. Each factor was grouped into the stakeholderinfluenced category namely "Investor" (A), "Customer" (B), "Employee" (C) and "Public" (D). For investor-influenced category, factors that may influence the perception of the investor are "sudden drop of share price and market capitalization" (A1), "services or sales progress disturbed" (A2), "ranking downgraded" (A3), "reduction of credit rating" (A4), "loss of new pipeline contracts" (A5) and "loss of sponsorship opportunity" (A6). "Loss of customer confidence" (B1) and "bad word-of-mouth among customers" (B2) are the customer-influenced factors. In the employee-influenced category, the factors are "CEO responds with unreasonable actions towards victims" (C1), "CEO neglects victims' welfare" (C2), "CEO hides facts about the accident" (C3), "CEO refuses to take responsibility" (C4), "CEO mismanages allocations to lobby politicians" (C5), "employees demotivated" (C6), "job applications for position reduced" (C7), "skilled worker resignations" (C8), "employee(s) caused accident" (C9). Finally, the public-influenced factors are "recurrence of similar accident" (D1), "loss of public trust" (D2), "severity of accident" (D3), "mishandling public reports" (D4), and the "negative media reports" (D5). These factors were rearranged into survey format to acquire the ranking of influence according to the expert judgment for prioritization purposes.

\section{B. Data collection}

This stage begins with the questionnaire designing stage. It was divided into two sections: demographic and the ranking of the factors influence the loss of pipeline owner reputation. The selected respondents were experts from a pipeline owner, Petroliam Gas Nasional (PETRONAS), who are the employees of the company with more than five years of experience working in the department of pipeline integrity management. These experts are the managers, engineers, and other technical personnel who previously or currently worked in that department. Interview sessions have been conducted to assist the respondents in the process of completing the questionnaire so that biasness and misunderstanding of the questionnaire can be reduced.

These respondents were asked to perform a pairwise comparison to identify the respective importance between two consecutive factors in each stakeholder-influenced factor using one of the multiple criteria decision-making methods, known as the analytical hierarchy process (AHP) fundamental scale. The scales are ranging from 1 to 9 , where scale 1 is considered both factors are equally importance; scale 3 is moderate importance; scale 5 is strong importance; scale 7 is very strong importance; and scale 9 is extreme importance. The scale of $2,4,6$ and 8 denoted the intermediate values. The consistency of pairwise comparison was checked using the consistency ratio (CR). If the consistency value of $C R$ is less than 0.1 , it proves that such pairwise comparison matrix consistency is satisfactory.

However, the pairwise comparison of factors can be a troublesome due to the number of comparison is highly dependent on the number of factors, $n$ i.e. $n(n$ $1) / 2$. Thus, the principle of data transformation scheme was used to ease the comparison procedure and reduces the number of questions in the questionnaire survey [15]. The AHP 9-point scale can be reduced into 5-point Likert scale in order to create simple and respondent-friendly types of questionnaire. The respondents were given a pipeline accident scenario prior to answer the questionnaire as follows: "A government-owned oil and gas company operated underground buried natural gas pipeline which transmits natural gas from refinery to the customers. Imagine if a section of this pipeline ruptured and exploded unexpectedly in a peak hour near a main road of a busy town, the consequences of 
the accidents that may be occurred are listed: 100 victims died and 50 more injured, 10 houses and 15 vehicles burned, 10 meter road melts, 12-inch diameter and 20 meter-long gas pipeline destroyed together with the 200 meter radius area were disturbed." According to the accident severity of that pipeline accident scenario, respondents were asked to rate each factor that influence the loss of reputation using 5-point Likert scale with range of 1 (not at all influence) to 5 (extremely influence).

\section{Data Analysis}

Collected responses given by the selected experts were recorded in the Statistical Package for Social Sciences (SPSS) for data reliability testing and statistical analysis in order to filter and affirm the quality of the data. Reliability coefficient for an acceptable internal consistency or the Cronbach's
Before the data was analyzed using AHP method via Super Decisions software, the relative importance index (RII) of each factor, which acts as a primary attempt to prioritize reputation loss factors based on the experts judgment, will be calculated using the following equation

$$
R I I=\frac{5 n_{5}+4 n_{4}+3 n_{3}+2 n_{2}+n_{1}}{5\left(n_{5}+n_{4}+n_{3}+n_{2}+n_{1}\right)}
$$

where $n$ is the frequency of the responses given for rating $i=1,2, \ldots, 5$. It is necessary to determine the rating scale due to the mean values obtained of RII is in decimal numbers. The 5-point rating scale of relative importance index classification is shown in Table 1.

Table 1. 5-point rating scale of relative importance index classification

\begin{tabular}{ccc}
\hline RII scale & RII score & Level of influence \\
\hline 1 & $20.00<\mathrm{RII}<36.00$ & Not at all influence \\
2 & $36.00 \leq \mathrm{RII}<52.00$ & Slightly influence \\
3 & $52.00 \leq \mathrm{RII}<68.00$ & Moderately influence \\
4 & $68.00 \leq \mathrm{RII}<84.00$ & Highly influence \\
5 & $84.00 \leq \mathrm{RII}<100.00$ & Extremely influence \\
\hline
\end{tabular}

alpha should fall within 0.7 to 0.9 for a newly developed questionnaire [16]. The Kruskal-Wallis test was conducted as the selected respondents fall in a group of more than two types of pipeline owner's personnel. It is hypothesized that there are no significant difference between responses given by these samples. As the level of confidence of $95 \%$ was selected and the significance level for this study was set at 0.05 , the test does not reject the null hypothesis if the $\chi^{2}$ value of significance is greater than 0.05 .
AHP is among the most appropriate methods to prioritize factors because they segregate weightage for each factor based on respondent preferences [17]. This software was developed by the founder of AHP method, T.L. Saaty, which can be downloaded without any charges for six months, especially for research and academic purposes. The dependency between factors of reputation loss was arranged according to the AHP framework based on the literature search. The relationship has to be designed in the main window of Super Decisions software as shown in Figure 1 before

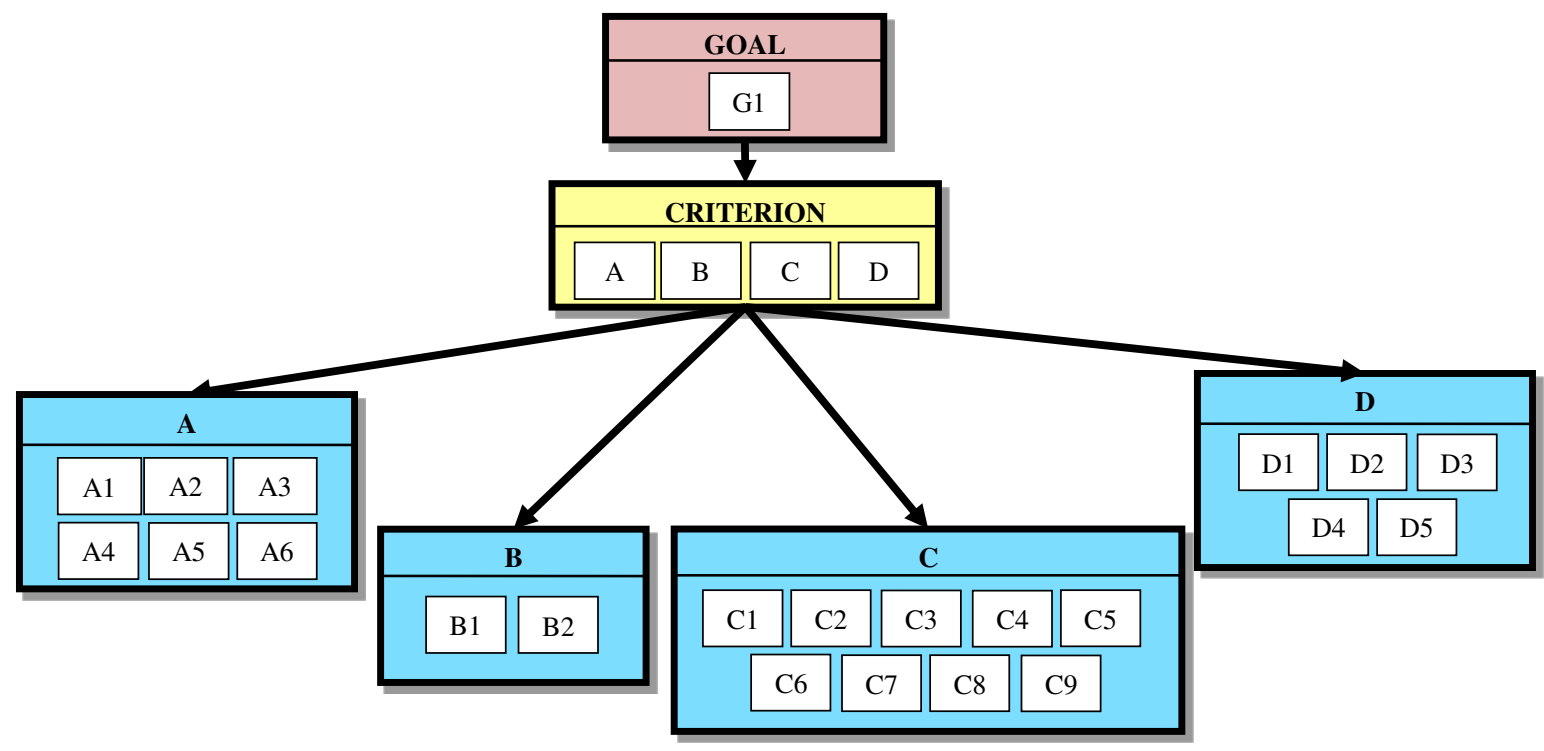

Figure 1. AHP framework in Super Decisions main window. 
data from experts' responses is stored. This hierarchical structure was constructed to create hierarchical influence between the goal (to prioritize the reputation loss factor), the criteria (stakeholders), and the subcriteria (reputation loss factors corresponding to the stakeholders). The ratings of each factor from all respondents are then keyed-in and the analysis runs. The priority vector or weightage can be obtained at the end of the analysis. An example of a pairwise comparison matrix is given in Table 2. Values of weightage for each factor from all respondents are then extracted; the average weightage values was calculated and ranked ascendingly. The factor with the highest weightage is the highest ranked factor among all.

\section{RESULTS AND DISCUSSION}

This questionnaire was distributed to the pipeline owner's personnel in order to gain a preliminary understanding on the influence of the factors based on the expert's judgments. A total of six experts have been successfully interviewed and the responses returned rate is $100 \%$. The reliability test of the questionnaire produced Cronbach's alpha of 0.90 . The value shows the design of the questionnaire is acceptable.

Based on the RII method, the score, level of influence, scale and ranking of reputation loss factors are as shown in the Table 3. According to the responses, most of the factors considered "highly influence"; however, none of them fell into "not at all influence" level by RII method. Of 22 factors of reputation loss, 16 grouped into the "highly influence" factor, five "moderately influence" and only one in "slightly influence" group.

However, the responses of rating the factors have to be tested to determine the significance of the

Table 2. An example of pairwise comparison matrix between the reputation loss factors

\begin{tabular}{|c|c|c|c|c|c|c|}
\hline Sub-criterion & $\mathrm{A} 1$ & $\mathrm{~A} 2$ & A3 & A4 & A5 & A6 \\
\hline $\mathrm{A} 1$ & 1 & 3 & 2 & 2 & 1 & 1 \\
\hline $\mathrm{A} 2$ & $1 / 3$ & 1 & $1 / 2$ & $1 / 2$ & $1 / 3$ & $1 / 3$ \\
\hline A3 & $1 / 2$ & 2 & 1 & 1 & $1 / 2$ & $1 / 2$ \\
\hline A4 & $1 / 2$ & 2 & 1 & 1 & $1 / 2$ & $1 / 2$ \\
\hline A5 & 1 & 3 & 2 & 2 & 1 & 1 \\
\hline A6 & 1 & 3 & 2 & 2 & 1 & 1 \\
\hline
\end{tabular}

Table 3. Relative importance index for reputation loss factors

\begin{tabular}{|c|c|c|c|c|}
\hline Code & RII score & Level of influence & RII scale & RII ranking \\
\hline A1 & 81.25 & Highly influence & 4 & 2 \\
\hline $\mathrm{A} 2$ & 79.69 & Highly influence & 4 & 3 \\
\hline A3 & 75.00 & Highly influence & 4 & 8 \\
\hline A4 & 70.31 & Highly influence & 4 & 13 \\
\hline A5 & 78.13 & Highly influence & 4 & 5 \\
\hline A6 & 73.44 & Highly influence & 4 & 10 \\
\hline B1 & 82.81 & Highly influence & 4 & 1 \\
\hline $\mathrm{B} 2$ & 73.44 & Highly influence & 4 & 10 \\
\hline $\mathrm{C} 1$ & 68.75 & Highly influence & 4 & 15 \\
\hline $\mathrm{C} 2$ & 71.88 & Highly influence & 4 & 12 \\
\hline C3 & 67.19 & Moderately influence & 3 & 18 \\
\hline $\mathrm{C} 4$ & 68.75 & Highly influence & 4 & 15 \\
\hline $\mathrm{C} 5$ & 67.19 & Moderately influence & 3 & 18 \\
\hline C6 & 78.13 & Highly influence & 4 & 5 \\
\hline $\mathrm{C} 7$ & 65.63 & Moderately influence & 3 & 20 \\
\hline $\mathrm{C} 8$ & 67.19 & Moderately influence & 3 & 18 \\
\hline C9 & 46.88 & Slightly influence & 2 & 22 \\
\hline D1 & 59.38 & Moderately influence & 3 & 21 \\
\hline D2 & 75.00 & Highly influence & 4 & 8 \\
\hline D3 & 76.56 & Highly influence & 4 & 6 \\
\hline D4 & 71.88 & Highly influence & 4 & 12 \\
\hline D5 & 68.75 & Highly influence & 4 & 15 \\
\hline
\end{tabular}


factors between different samples to improve the confidence level. The sample between the differences in job position, i.e. manager, engineer and the technical personnel was tested. Results obtained from SPSS software shows that the asymptotic significant values for all factors using Kruskal-Wallis test are exceeding 0.05, it can be concluded that the null hypothesis cannot be rejected. Hence, there is no significance difference of responses between samples of different types of job position of the pipeline owner personnel. Consequently, ranking of the reputation loss factors can be executed despite the mixture of respondents' working background.

The ranking process of the factor can be done by rearranging ascendingly the calculated RII score obtained from RII method. The factor "loss of customer confidence" (B1) ranked the highest with RII score of 82.81 and factor "employee(s) caused accident" (C9) scored 46.88 and nominated as the lowest ranked factor. Similarly, AHP method produces the same result of the highest and lowest rank of factors as RII method as shown in Figure 2. The factor "loss of customer confidence" (B1) ranked the highest with priority vector of 0.1700 and factor "employee(s) caused accident" (C9) is the lowest ranked factor with 0.0110 value of priority vector.

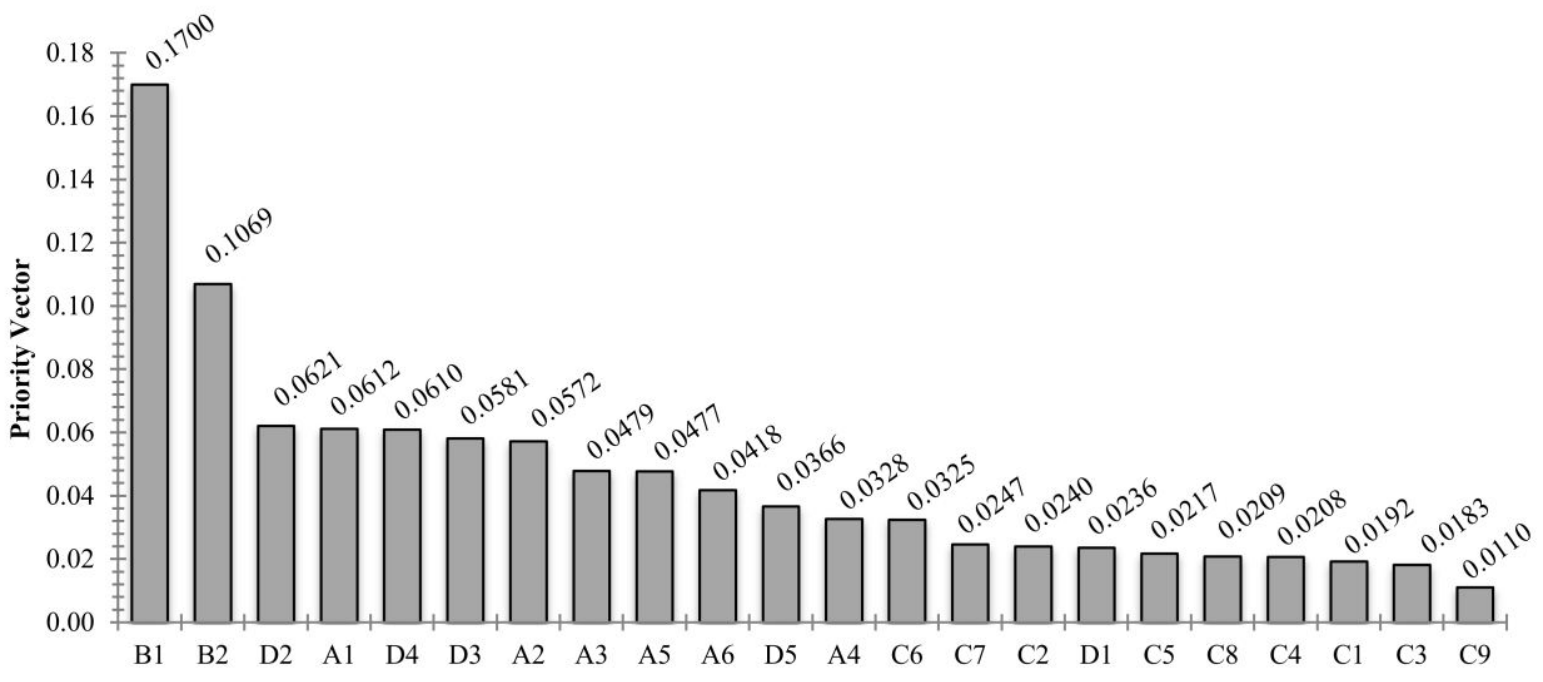

Reputation Loss Factor

Figure 2. The priority vector of all reputation loss factors arranged in descending manner.
The difference between these two methods can be seen on the RII score and the priority vector obtained from AHP method. The priority vector for all factors is different between one and another. On the other hand, there are several factors consists of similar RII scores, e.g. "loss of new pipeline contracts" (A5) and "employees demotivated" (C6) with 78.13 score, "ranking downgraded (A3) and "loss of public trust" (D2) with 75.00 score, "loss of sponsorship opportunity" (A6) and "bad word-of-mouth among customers" (B2) with 73.44 score, "CEO responds with unreasonable actions towards victims" (C1), "CEO refuses to take responsibility" (C4), and (D5) with 68.75 score, "CEO hides facts about the accident" (C3), "CEO mismanages allocations to lobby politicians" (C5), "skilled worker resignations" (C8) and 67.19 score. As a result, the ranking of these factors which consists a similar RII scores are also fell in the same rank, they are ranked at number $5,10,12,15$, and 18 , respectively. It happens due to the procedures of RII method where it directly utilized the value of rating scale (1 to 5), which the result can be almost similar among the factors within the same group of level of importance, consequently incapable to provide the priority of the factors. In contrast, the AHP method manipulates the rating given from the responses in order to gain the importance between two factors using pairwise comparison method for all factors. It contributes to a better segregation of importance of all factors, which simultaneously produces different values of priority of each factor and prioritizes the factor successfully.

Based on the result, the experts have come to an agreement that the customer is the pipeline owner's highest priority; losing their confidence is the major concern which the demand for oil and gas product and services is potentially to be affected. It approves that the degradation of a company reputation will affect its profit $[10,11]$. Furthermore, customers' affective feelings towards the company are reason towards their loyalty
[18]. Even so, accident cause by human error is worryless according to the experts. It is due to the fact that the employee is presumed fully trained to operate the pipeline with high safety consciousness. Nevertheless, the malfunction of equipment components and/or minor negligence of personnel during operation and maintenance work may contribute to the "domino effect" of fire and explosions [19]. Hence, it was ranked the least by the experts. 


\section{CONCLUSION}

The factors that contribute to reputation loss of a company can be determined and prioritized by the aid of AHP method. Despite the difficulties in quantifying the factors into monetary values, prioritization is presumed to be another solution to quantify the reputation loss factor in the future. The qualitative nature of the factors was transformed into quantitative manner with the help of AHP multi-criteria decision making method. It shows that qualitative factors are possible to be quantified monetarily by further research in the future by referring to the definition of each factor itself. Thus, it is predicted that a comprehensive pipeline risk assessment on damaged by corrosion is achievable with the inclusion of reputation loss in the evaluation of damage impact or consequence assessment. Hence, PIMP can be implemented comprehensively and simultaneously improve the company's annual profit margin.

\section{ACKNOWLEDGMENTS}

The author gratefully acknowledges the support provided by the Malaysia Ministry of Education [grant number 4F530].

\section{REFERENCES}

[1] W. K. Muhlbauer, "Pipeline Risk Management Manual, Third Edition," Gulf Publishing Company, Houston, Texas, 2004, pp. 10-55.

[2] N. Yahaya, N. M. Noor, S. R. Othman, K.S. Lim, M.M. Din, "New technique for studying soil-corrosion of underground pipeline," J. Appl. Sci., vol. 11, no. 9, pp. 1510-1518, 2011.

[3] N. Yahaya, N. M. Noor, M. M. Din, S. H. M. Nor, "Prediction of $\mathrm{CO} 2$ Corrosion growth in submarine pipelines,” Malays. J. Civ. Eng., vol. 21, no. 1, pp. 69-81, 2009.

[4] F. I. Khan, M. Haddara, "Risk-Based Maintenance (RBM): A new approach for process plant inspection and maintenance," Process Saf. Prog., vol. 23, no. 4, pp. 252$265,2004$.

[5] N. S. Arunraj, J. Maiti, "A methodology for overall consequence modeling in chemical industry," J. Hazard. Mater., vol. 169, pp. 556-574, 2009.
[6] R. L. M. Dunbar, J. Schwalbach, "Corporate reputation and performance in Germany," Corp. Reputation Rev., vol. 3, no. 2, pp. 115-123, 2000

[7] C. d. Bie, "Exploring Ways to Model Reputation Loss," Erasmus University Rotterdam, Netherlands, 2006.

[8] P. J. Firestein, "Reputation Assessment: The OPEN Perception Study ${ }^{\mathrm{TM}}$," Global Strategic Communication, Inc., New York, 2004

[9] C.J. Fombrun, "Reputation: Realizing value from the corporate image," Harvard Business School Press, United States of America, 1996.

[10]K. Cravens, E. G. Oliver, S. Ramamoorthi, "The reputation index: Measuring and managing corporate reputation,” Eur. Manag. J., vol. 21, no. 2, pp. 201-212, 2003.

[11]K. Money, C. Hillenbrand, "Beyond reputation measurement: Placing reputation within a model of value creation by integrating existing measures into a theoretical framework," J. Gen. Manag., vol. 32, no. 1, pp. 1-12, 2006.

[12] L. Zardasti, N. Yahaya, A. Valipour, A. S. A. Rashid, N. M. Noor, "Review on the identification of reputation loss indicators in an onshore pipeline explosion event, J. Loss Prev. Proc., vol. 48, pp. 71-86, 2017.

[13] L. Zardasti, N.M. Hanafiah, N.M. Noor, N. Yahaya and A.S.A. Rashid, "The consequence assessment of gas pipeline failure due to corrosion," Solid State Phenom, vo. 227, pp. 225-228, 2015.

[14] L. Zardasti, N.M. Hanafiah, N.M. Noor and N. Yahaya, "Prioritization of reputation loss factor subject to pipeline explosion," Asian J. Sci. Res., vol.8, no.4 pp. 442-453, 2015.

[15] Z. Chen, "A cybernetic model for analytic network process," 9th Int. Conf. Machine Learning and Cybernetics, Qingdao, China, pp. 1914-1919, 2010.

[16] J. A. Gliem and R. R. Gliem, "Calculating, interpreting, and reporting Cronbach's alpha reliability coefficient for Likert-type scales," Midwest Research-to-Practice Conf. Adult, Continuing, and Community Education, Columbus, Ohio, pp. 82-88, 2003

[17] T. L. Saaty, "Decision making with the analytic hierarchy process,” Int. J. Serv. Sci, vol. 1, no. 1, pp. 83-98. 2008

[18] Y. Zhang, "A study of corporate reputation's influence on customer loyalty based on PLS-SEM model," Int. Bus. Res., vol. 2, pp. 28-35, 2004

[19] F. I. Khan and S. A. Abbasi, "Major accidents in process industries and an analysis of causes and consequences," J. Loss Prev. Proc., vol. 12, pp. 361-378, 1999. 